\title{
Colony-Stimulating Factors as Promoters of Ameboid Microglia
}

\author{
Dana Giulian and Jeff E. Ingeman \\ Department of Neurology and Program of Neuroscience, Baylor College of Medicine, Houston, Texas 77030
}

Immunomodulators were tested for their ability to stimulate proliferation and biologic activity of ameboid microglia. Only the colony-stimulating factors (CSFs), multipotential-CSF (multi-CSF) and granulocyte/macrophage-CSF (GM-CSF), were potent mitogens for microglia. Other immunomodulators, including interleukin-1, interleukin-2, interferon gamma, tumor necrosis factor, or granulocyte-CSF (G-CSF), had no effect upon microglial growth in vitro. Multi-CSF or GM-CSF were also observed to induce more rapid phagocytosis of polystyrene microspheres by cultured ameboid cells.

In order to determine which immunomodulators alter brain inflammatory responses in vivo, we infused recombinant forms of GM-CSF, multi-CSF, macrophage-CSF, or G-CSF into the cerebral cortex of rats. Within $48 \mathrm{hr}$ after infusion multi-CSF or GM-CSF stimulated the appearance of large numbers of mononuclear phagocytes at the site of injection. These same factors also accelerated the clearance of polystyrene microspheres from the brain. Our observations indicate that certain classes of immunomodulators which are mitogens and activators of ameboid microglia in vitro amplify the inflammatory response of the CNS in vivo by action upon intrinsic brain mononuclear phagocytes.

The activation of mononuclear phagocytes is an important, early cellular response to brain injury (Giulian, 1987). Inflammatory cells migrate to the site of CNS damage, proliferate, release a variety of secretory factors, and engulf tissue debris (Rio-Hortega, 1932; Giulian, 1987). A growing body of evidence indicates that mononuclear phagocytes are effector cells in the brain that mediate not only the acute inflammatory response (Oehmichen, 1983) but also the subsequent astrogliotic reaction and neovascularization occurring at wound sites (Giulian and Lachman, 1985; Giulian et al., 1986a, b, 1988a). The regulatory factors to control migratory, proliferative, phagocytic, and secretory functions of brain mononuclear phagocytes are unknown.

The 2 major classes of mononuclear phagocytes in the CNS represent intrinsic and extrinsic brain cell populations (RioHortega, 1932; Giulian, 1987). Blood-borne macrophage are extrinsic cells that invade the brain at sites of injury as demonstrated in penetrating wounds (Rio-Hortega, 1932; Konigsmark and Sidman, 1963; Ling, 1981; Giulian, 1987). In contrast, microglia are intrinsic brain cells that have an ameboid morphology during embryogenesis (Ling, 1981; Matsumoto and

Received Feb. 3, 1988; revised Apr. 13, 1988; accepted Apr. 14, 1988.

This work was supported by Grants NS23113 and NS25673 from the NINCUS, Grant EY04915 from the NEI, and support from the March of Dimes. We thank Mikla Noponen, Jocelyn Chen, and Johnson George for technical assistance.

Correspondence should be addressed to Dana Giulian at the above address.

Copyright (C) 1988 Society for Neuroscience $0270-6474 / 88 / 124707-11 \$ 02.00 / 0$
Ikuta, 1985; Giulian and Baker, 1986; Giulian et al., 1988b) and a ramified shape in mature normal brain (Rio-Hortega, 1932; Giulian and Baker, 1986). As proposed by Rio-Hortega (1932), ramified microglia revert to the ameboid type at the time of CNS damage (Kreutzberg and Barron, 1976; Kreutzberg and Graber, 1986; Giulian, 1987). Thus, both intrinsic and extrinsic brain mononuclear phagocytes take part in CNS inflammation with the type of injury determining the composition of the inflammatory cell response (Konigsmark and Sidman, 1963; Kreutzberg and Barron, 1976; Boya et al., 1979; Brierley and Brown, 1982; Innocenti et al., 1983; Giulian, 1987). Although ameboid microglia have macrophage-like properties (RioHortega, 1932; Giulian and Baker, 1986; Giulian, 1987), in vitro studies show that these cells may be distinguished from other classes of mononuclear phagocytes by morphology, histochemical features, and proliferative capacity (Giulian and Baker, 1986; Giulian, 1987). We sought to uncover signals that influcnce the biologic actions of ameboid microglia.

Colony-stimulating factors (CSFs) are glycoproteins that regulate the survival, proliferation, and differentiation of hematopoietic cells, including mononuclear phagocytes (Metcalf, 1985). Four types of CSFs have been identified (Clark and Kamens, 1987), each with varying degrees of specificity of action upon bone marrow-derived progenitor cells: granulucyte-CSF (G-CSF), granulocyte-macrophage-CSF (GM-CSF), macrophage-CSF (M-CSF), and multipotential-CSF (multi-CSF). In addition to their effects on progenitor populations, CSFs also influence more mature mononuclear phagocytes (Metcalf, 1985; Clark and Kamens, 1987).

In order to identify signals that mediate inflammation in the CNS, we have tested recombinant forms of the CSFs as well as other immunomodulators for their ability to promote proliferation and biologic activity of ameboid microglia. Our observations suggest that multi-CSF and GM-CSF amplify inflammatory responses in the central nervous system by direct action upon intrinsic brain mononuclear phagocytes.

\section{Materials and Methods}

Glial cell cultures. Mixed glial cell cultures were prepared as described earlier (Giulian and Baker, 1985) from dissociated cerebral cortex of newborn albino rat (Holtzman, Madison, WI). Cells were placed in 35 $\mathrm{mm}$ plastic dishes upon poly(L-lysine)-coated glass coverslips in chemically defined medium (Bottenstein and Sato, 1979) containing $10 \%$ fetal bovine serum; after $48 \mathrm{hr}$, cells were grown in chemically defined medium.

Ameboid microglia were isolated from the brains of newborn rat using the method of Giulian and Baker (1986). Cells were grown on glass coverslips [without poly(L-lysine) coating] for $24 \mathrm{hr}$ in chemically defined medium plus $10 \%$ fetal bovine serum and then transferred to chemically defined medium alone. Resident peritoneal macrophages were isolated from adult albino rats (Holtzman, Madison, WI) by the 
method of Daems (1980) and grown under conditions identical to those of microglia.

Glial cell identification. Ameboid microglia were identified by fluorescence microscopy using acetylated low-density lipoprotein (ac-LDL) bound to the fluorescent probe $1,1^{\prime}$-dioctadecyl-1,-3,3,3',3'-tetramethyl-indo-carbocyanine (DiI) (Pitas et al., 1981; Giulian and Baker, 1986). In vitro labeling was carried out in chemically defined medium with 5$10 \mu \mathrm{g} / \mathrm{ml}$ of DiI-ac-LDL for $6 \mathrm{hr}$ at $37^{\circ} \mathrm{C}$. The DiI-ac-LDL was obtained from Biomedical Technologies Inc. (Cambridge, MA). Cultured ameboid cells were also visualized by monitoring phagocytosis of fluorescent polystyrene microspheres $(0.7 \mu \mathrm{m}$, Covaspheres Particles, FX Green, Duke Scientific, Palo Alto, CA) and by histochemistry for nonspecific esterase (Koski et al., 1976).

Indirect immunofluorescence techniques were used to identify astroglia containing glial fibrillary acidic protein (GFAP) and oligodendroglia containing galactocerebroside (GC) (Giulian et al., 1986a).

Bioassays. In order to test for mitogenic effects, cell cultures grown in $1.5 \mathrm{ml}$ chemically defined medium were incubated with increasing concentrations of immunomodulators and growth factors for $72 \mathrm{hr}$. Proliferation of ameboid microglia, astroglia, oligodendroglia, and peritoneal macrophage were monitored by scoring the number of specifically labeled cells in 9 randomly selected fields $\left(0.314 \mathrm{~mm}^{2}\right)$ from each of 3 or more coverslips. The data were expressed as fold increased over control cultures incubated with matching aliquots of PBS ranging from 1 to $50 \mu \mathrm{l} / \mathrm{ml}$.

Freshly isolated ameboid microglia were plated in 96 well plates (50,000 cells/well) for $24 \mathrm{hr}$ in $200 \mu \mathrm{l}$ of chemically defined medium containing $10 \%$ fetal bovine serum. Cells were then incubated in 200 $\mu 1$ of chemically defined medium that contained 5 units of a CSF for $48 \mathrm{hr}$. ${ }^{3} \mathrm{H}$-thymidine, $3 \mathrm{mCi}$, was added to each well for the last $10 \mathrm{hr}$ of the incubation period. At the end of the $48 \mathrm{hr}$ incubation period, cells were frozen for $1 \mathrm{hr}$ at $-70^{\circ} \mathrm{C}$. Radiolabeled DNA released from cells lyzed with deionized water onto glass filter paper (Skatron Harvester; Sterling, VA) was measured by liquid scintillation counting.

Phagocytic activity was measured in vitro with fluorescence microscopy by scoring the number of fluorescently labeled polystyrene microspheres $\left(0.7 \mu \mathrm{m}\right.$ in diameter) engulfed within $12 \mathrm{hr}$ at $37^{\circ} \mathrm{C}$ by Dilac-LDL $(+)$ cells. In order to test the ability of brain to remove debris, we injected $2 \mu \mathrm{l}$ of immunomodulators in PBS containing polystyrene microspheres $(0.0005 \% \mathrm{wt} / \mathrm{vol})$. Particle clearance from the brain was measured by determining the number of microspheres found in serial sections taken from the site of injection. Brains were fixed in $3.5 \%$ formaldehyde buffered with PBS, frozen in OCT compound (TissueTek, Naperville, IL), and cut on a freezing microtome (Minitome, Needham, MA) into $10-\mu \mathrm{m}$-thick serial sections in the coronal plane.

Injection of immunomodulators into the brain. To study the effects of CSFs in vivo, we injected small volumes of material into the cerebral cortex of albino rats. Adult rats (250-300 gm, Holtzman, Madison, WI) were deeply anesthetized by intraperitoneal injection $(0.8-1.2 \mathrm{ml}$ of a mixture containing $8.5 \mathrm{mg} / \mathrm{ml}$ xylazine, $42 \mathrm{mg} / \mathrm{ml}$ ketamine hydrochloride, and $1.4 \mathrm{mg} / \mathrm{ml}$ acepromazine maleate) and placed in a stereotaxic device (David Kopf, Inc.). After the scalp was reflected, burr holes through the skull were positioned over the cerebral cortex $4.5 \mathrm{~mm}$ caudal to bregma and $4.0 \mathrm{~mm}$ lateral to the sagittal suture. Using a $5.0 \mu 1$ syringe (Hamilton, Reno, NE) mounted in the stereotaxic device, we infused $1.0 \mu \mathrm{l}$ of PBS containing an immunomodulator at a depth of $1.5 \mathrm{~mm}$ from the surface of the brain over a 2 min interval. Control injections of PBS alone were made in an identical location on the contralateral side. The syringe needle was slowly withdrawn and the scalp closed with wound clips. Forty-eight hours later, the animals were deeply anesthetized, and a cylindrical biopsy $(2.0 \times 1.0 \mathrm{~mm})$ was removed rapidly from the injection site following cardiac perfusion with heparinPBS solution (500 USP units/liter). The tissue sample was then incubated for $6 \mathrm{hr}$ at $37^{\circ} \mathrm{C}$ in chemically defined medium containing $10 \mu \mathrm{g} /$ $\mathrm{ml}$ DiI-ac-LDL. The tissue was fixed with $3 \%$ formaldehyde in PBS for $1 \mathrm{hr}$ and viewed using fluorescence microscopy and photographed immediately.

Immunomodulators and growth factors. Recombinant forms of immunomodulators used in this study included human granulocyte-colony stimulating factor (rh-G-CSF) from Amgen Biologicals, murine granulocyte-macrophage colony-stimulating factor (rm-GM-CSF) from Genzyme Corporation, and human macrophage-colony-stimulating factor (rh-M-CSF), a gift from Dr. Peter Ralph, Cetus Corporation. Two forms of murine multipotential-colony-stimulating factor (multi-CSF, also referred to as interleukin 3 or IL-3) were used, a murine cell linederived type (m-IL-3) obtained from Genzyme and a recombinant mu-

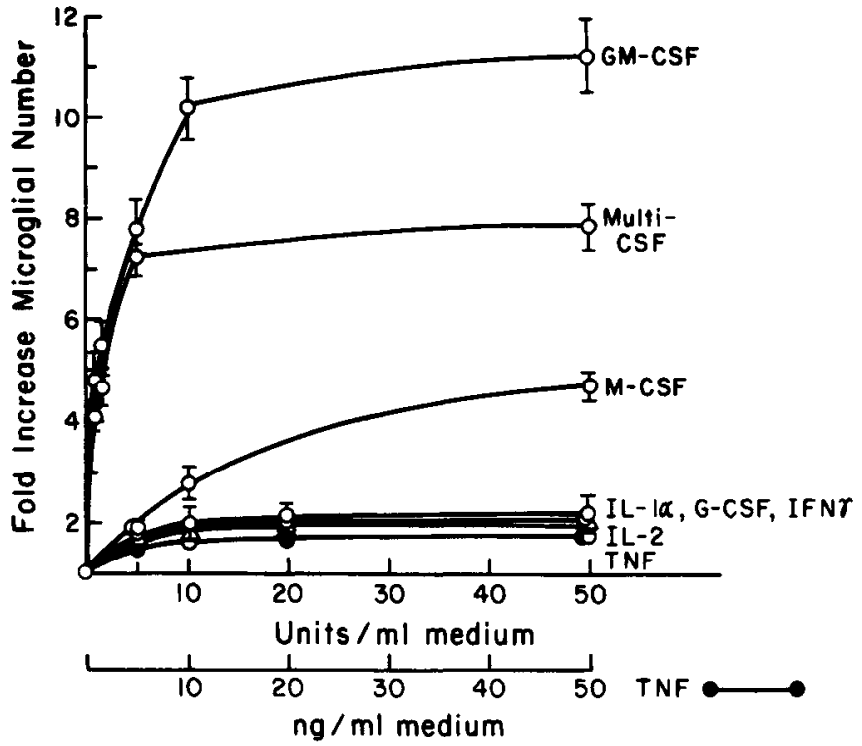

Figure 1. Proliferative effects of immunomodulators upon ameboid microglia. Mixed cell cultures from newborn rat brain were grown on coverslips in chemically defined medium containing various immunomodulators. As shown, only the colony-stimulating factors rm-GMCSF, m-multi-CSF, and rh-M-CSF stimulated growth of microglia. Data are mean values expressed as fold increase in cell number \pm SEM compared with control cultures treated with equivalent aliquots of PBS $(5-50 \mu 1)$ that lacked immunomodulators. At least 5 cultures were used to determine each mean value.

rine form (rm-multi-CSF), which was a gift from DNAX Corp. The rmmulti-CSF (provided as a COS cell line supernatant) required further purification by high-performance liquid chromatography using a $\mathrm{C} 8$ reverse-phase column $(4.6 \times 75 \mathrm{~mm}$; Beckman, Palo Alto, CA $)$ with a $0-55 \%$ gradient of acetonitrile in water containing $0.1 \%$ trifluoroacetic acid. Recombinant forms of human tumor necrosis factor alpha (rhTNF alpha), human interleukin 1 alpha (rh-IL-1 alpha), human interleukin 2 (rh-IL-2), and murine interferon gamma (rm-IFN gamma) were obtained from Amgen Biologicals, Cistron Technologies, Cetus Corp., and Genentech, respectively. All purified recombinant immunomodulators were found to have less than $0.05 \mathrm{ng} / \mathrm{ml}$ of endotoxin as shown by the Limulus amebocyte lysate assay (Cape Cod Associates).

Other growth factors that were tested included recombinant human insulin-like growth factor 1 (rh-IGF-1, also referred to as somatomedin C) from Amgen Biologicals, recombinant human transforming growth factor beta (rh-TGF beta) from Amgen Biologicals, epidermal growth factor (EGF) from Collaborative Research, acidic fibroblast growth factor (FGF) from California Biotechnology, and recombinant basic FGF from Amgen Biologicals.

\section{Results}

A proliferation of ameboid microglia occurs during brain development and at sites of brain injury (Rio-Hortega, 1932; Ling, 1981). Since earlier work from our laboratory suggested that soluble factors help to regulate the number of microgroglia found in culture (Giulian and Baker, 1986), we screened a variety of immunomodulators for mitogenic effects upon ameboid cells.

\section{Identification of microglial mitogens}

GM-CSF and multi-CSF after a $72 \mathrm{hr}$ incubation period increased the number ameboid microglia found in mixed glial cultures 7- to 10-fold above that in control cultures (Fig. 1). Saturation of the mitogenic responses occurred at concentrations of about $10 \mathrm{units} / \mathrm{ml}$ for either factor. Although less effective, M-CSF (50 units $/ \mathrm{ml}$ ) also stimulated microglial growth with a 4-fold increase in cell number. Importantly, none of the 

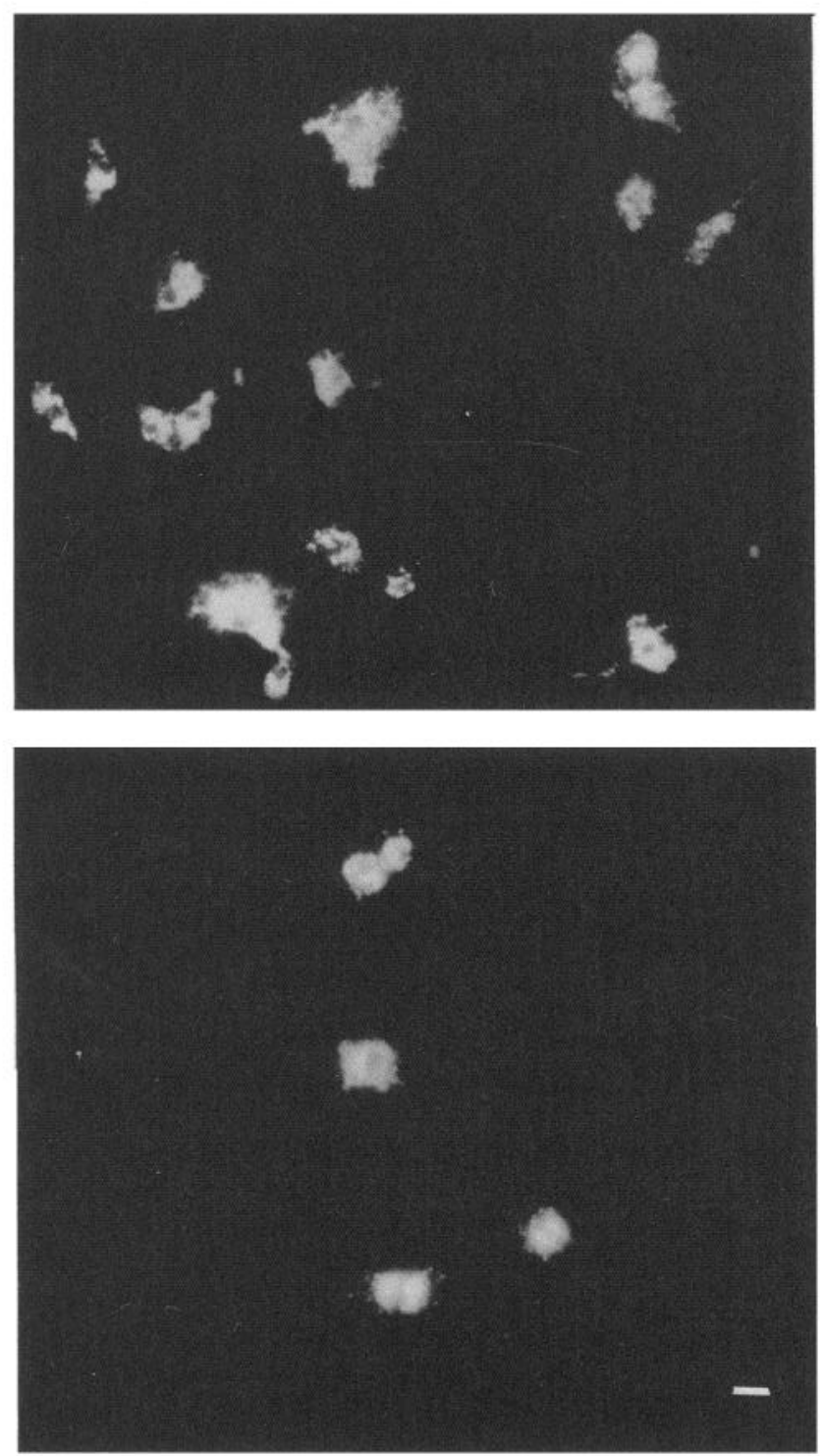

Figure 2. Fluorescent photomicrographs showing the mitogenic effects of multi-CSF on mixed glial cell cultures. Cells grown in chemically defined medium containing 5 units of recombinant multi-CSF for 72 $\mathrm{hr}(t o p)$ had a marked increase in the number of DiI-ac-LDL(+) ameboid microglia compared with control cultures (bottom). Scale bar, 20 $\mu \mathrm{m}$.

other immunomodulators examined-G-CSF, IL-1, IL-2, TNF, or IFN gamma-showed growth-promoting effects upon ameboid microglia. In testing other growth factors (EGF, FGF, IFG1 , and TGF beta), we found that only acidic and basic FGF had a small, though significant proliferative effect upon DiI-acLDL (+) microglia found in mixed glial cultures (Fig. 3).

Further study was necessary to determine if the mitogenic effects of the CSFs and FGF in mixed cell preparations were mediated by direct action upon microglia. Isolated ameboid microglia [ $>95 \%$ homogeneous DiI-ac-LDL $(+)$ cell population] showed stimulated proliferation when incubated with GM-CSF or M-CSF (Figs. 4, 5) as found with mixed glial cultures. We also observed direct mitogenic effects of native and recombinant forms of multi-CSF (Table 1) upon ameboid microglia, as reported previously by our laboratory (Giulian and Baker, 1986) and recently confirmed by Frei and Fontanna (1986). The ac-

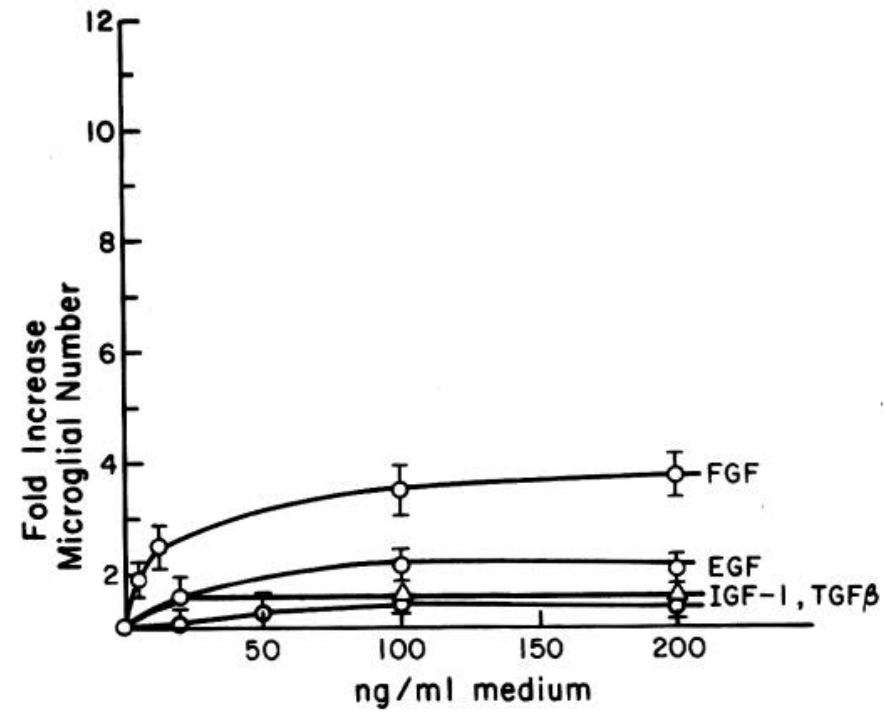

Figure 3. Proliferative effects of growth factors upon ameboid microglia. Mixed cell cultures from newborn rat brain were grown in chemically defined medium containing various protein growth factors. Only basic recombinant FGF was found to increase the number of DiI-acLDL $(+)$ ameboid cells. Data are mean values \pm SEM expressed as fold increase in cell number compared with control cultures. At least 5 cultures were used to determine each mean value.

tions of the CSFs were cell specific, with no apparent growthpromoting effects upon $\mathrm{GFAP}(+)$ astroglia or $\mathrm{GC}(+)$ oligodendroglia (Fig. 6).

Recombinant basic FGF was not a mitogen for isolated ameboid microglia (Fig. 4), although it stimulated microglial proliferation in cultures containing astroglia and oligodendroglia (Fig. 3) In contrast, the mitogenic effects of FGF upon astroglia (Fig. 6) occurred by a direct action (Pruss et al., 1981; Giulian et al., 1986a), as shown in highly purified cell preparations. Since ameboid microglia grow rapidly atop monolayers of astroglia,

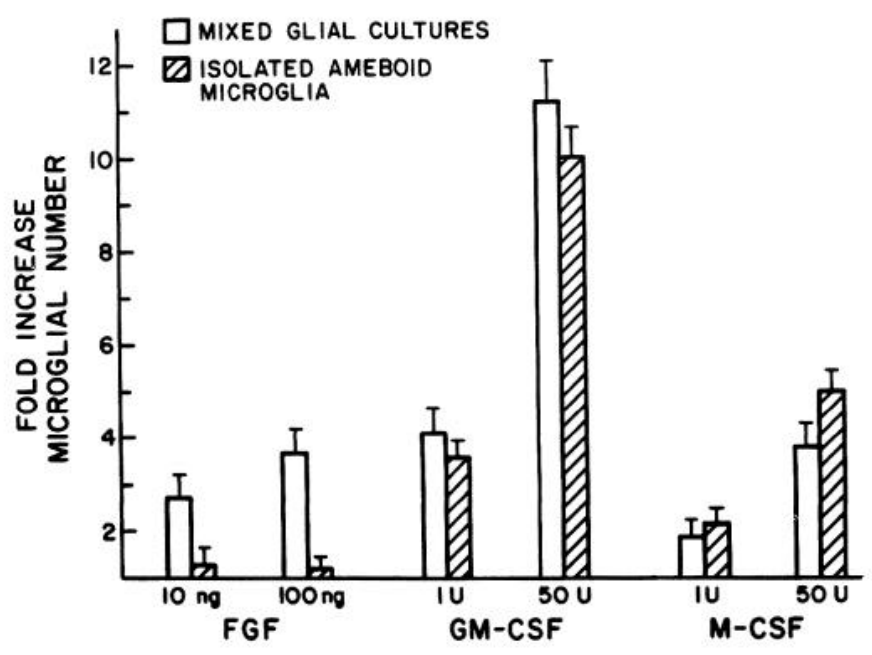

Figure 4. Direct proliferative effects of factors upon isolated ameboid microglia. Low and high doses (in $1 \mathrm{ml}$ of culture medium) of recombinant basic FGF, rm-GM-CSF, and rh-M-CSF were tested for their mitogenic effects upon ameboid microglia isolated from newborn rat brain. GM-CSF and M-CSF stimulated proliferation of isolated microglia [ $>93 \%$ DiI-ac-LDL(+) cells]. In contrast, recombinant basic FGF only promoted growth of microglia found in mixed cultures $[<10 \%$ DiI-ac-LDL(+) cells]. 
4710 Giulian and Ingeman - CSFs as Promoters of Ameboid Microglia
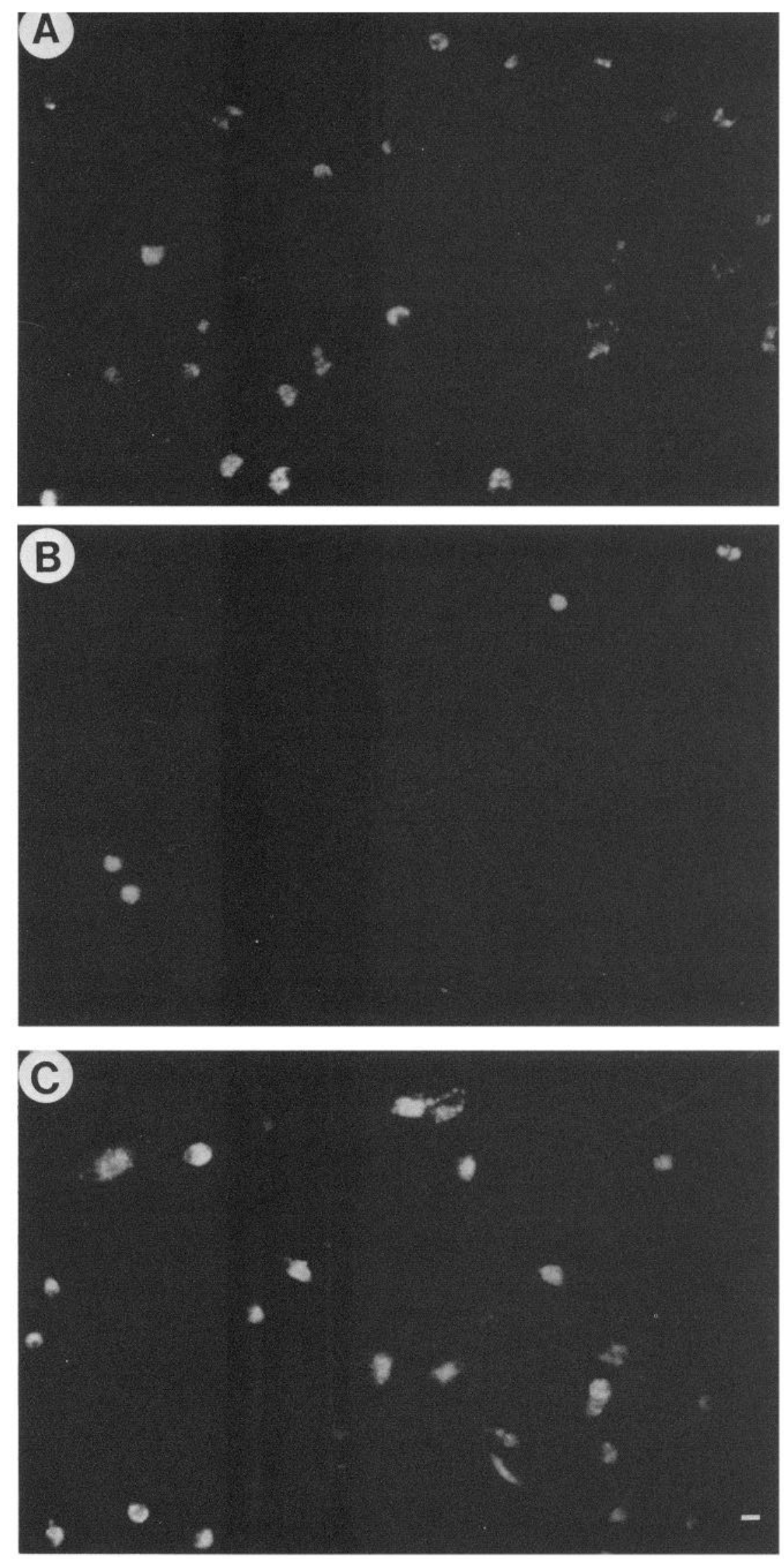

Fluorescence photomicrographs showing the effects of CSFs upon isolated ameboid microglia. There is a 5- to 6-fold increase in DiI-ac-LDL + ) microglia incubated for $72 \mathrm{hr}$ with 5 units of rm-GM-CSF $(A)$ or 50 units of rh-M-CSF $(C)$ compared with those treated with $100 \mathrm{ng}$ recombinant basic FGF $(B)$. Scale bar, $20 \mu \mathrm{m}$. 

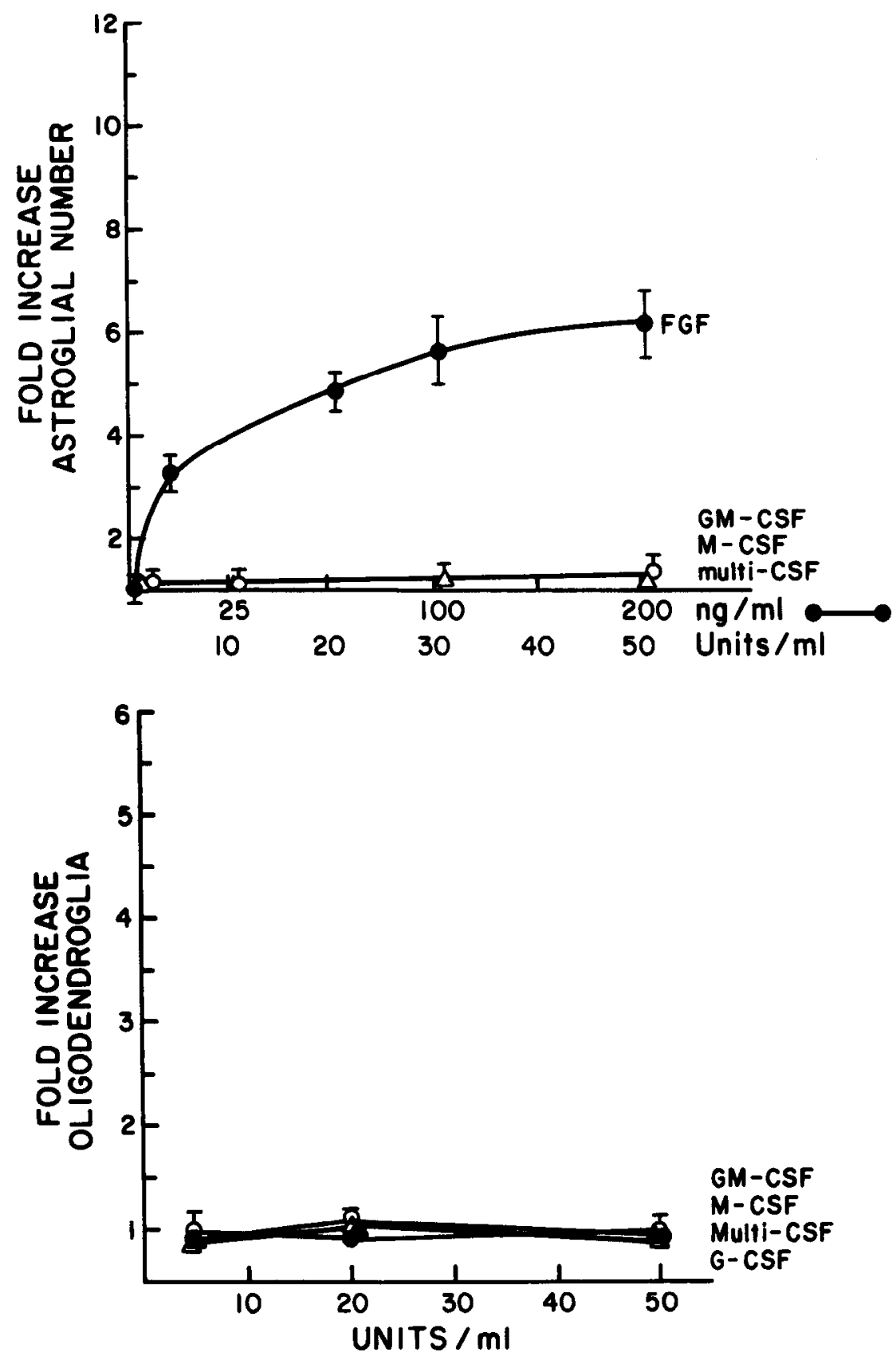

Figure 6. Growth factors and specificity of action in vitro. Colony-stimulating factors had no growth promoting-effects upon GFAP $(+)$ astroglia $(t o p)$ or $\mathrm{GC}(+)$ oligodendroglia (bottom). Recombinant basic FGF was a potent mitogen for astroglia (top). Data are mean values \pm SEM expressed as fold increase compared with control cultures. At least 5 cultures were used to determine each mean value.

\begin{tabular}{ll}
\hline $\begin{array}{l}\text { Table 1. CSFs increase } \\
\text { microglia }\end{array}$ & $\begin{array}{l}\text { Incorporated }{ }^{3} \mathrm{H}- \\
\text { thymidine (counts/ } \\
\text { min) }\end{array}$ \\
Factor treatment & $507 \pm 26$ \\
\hline Control $(n=9)$ & $1623 \pm 423^{a}$ \\
Multi-CSF (3) & $1695 \pm 153^{b}$ \\
GM-CSF $(5)$ &
\end{tabular}

Freshly isolated ameboid microglia were plated in 96 well plates $(50,000$ cells per well) for $24 \mathrm{hr}$ in $200 \mu \mathrm{l}$ of chemically defined medium containing $10 \%$ fetal bovine serum. Cells were then incubated in $200 \mu$ l of chemically defined medium that contained 5 units of a CSF for $48 \mathrm{hr}$. Three $\mathrm{mCi}$ of ${ }^{3} \mathrm{H}$-thymidine were added to each well for the last $10 \mathrm{hr}$ of the incubation period. Data are expressed as mean counts per $\mathrm{min} \pm \mathrm{SEM}$.

${ }^{a} p<0.05$.

${ }^{b} p<0.001$ by Student's $t$ test using the Bonferroni correction (Godfrey, 1985).
Table 2. Effects of CSFs upon peritoneal macrophage

\begin{tabular}{ll} 
Factor treatment & $\begin{array}{l}\text { Increase in macrophage } \\
\text { number (fold) }\end{array}$ \\
\hline Multi-CSF & $1.0 \pm 0.1$ \\
G-CSF & $1.3 \pm 0.2$ \\
M-CSF & $2.5 \pm 0.1$ \\
GM-CSF & $1.9 \pm 0.2$ \\
Basic FGF & $1.1 \pm 0.2$
\end{tabular}

Resident peritoneal macrophage were grown on glass coverslips in chemically defined medium containing 10 units of a recombinant CSF or $100 \mathrm{ng}$ FGF. After $72 \mathrm{hr}$, cells were labeled with DiI-ac-LDL. The data are expressed as mean fold increase in DiI-ac-LDL $(+)$ macrophage \pm SEM compared with untreated control cultures. Each value represents a mean score obtained from at least 5 cultures. 

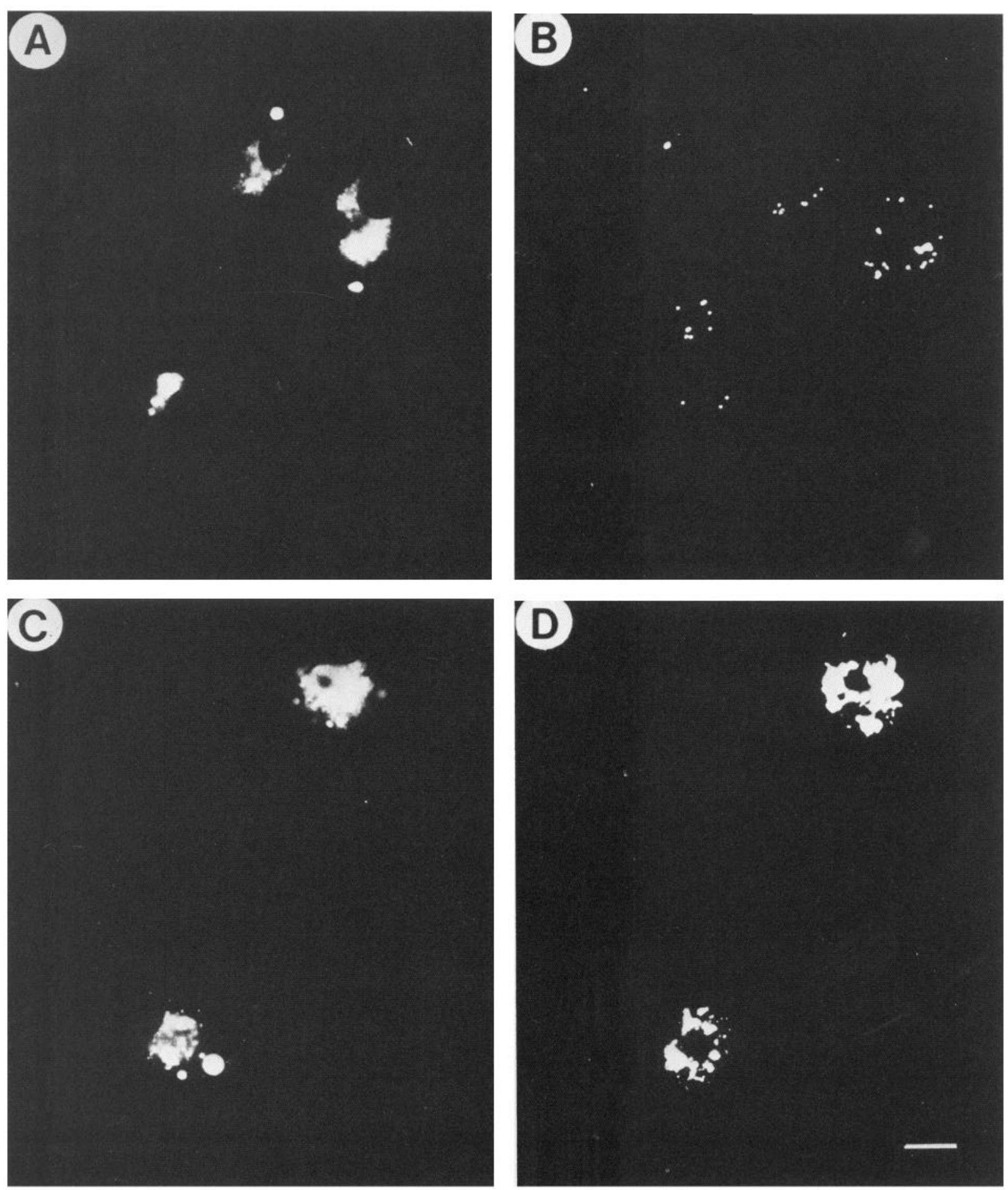

Figure 7. Fluorescence photomicrographs showing the stimulated phagocytic activity in ameboid microglia after incubation with 10 units/ml medium of rm-GM-CSF. Ameboid cells are identified by DiI-ac-LDL in control $(A)$ and GM-CSF-treated $(C)$ cultures. As shown in $D$, there is an increased number of fluorescently labeled microspheres engulfed by GM-CSF activated cells compared with control cells $(B)$. Scale bar, $20 \mu \mathrm{m}$.

it is possible that FGF stimulates astroglia, which, in turn, supports rapid proliferation of microglia.

Dose-response curves (Fig. 1) indicated that GM-CSF and multi-CSF were the most potent mitogens for ameboid microglia. By contrast, M-CSF was a mitogen for resident peritoneal macrophage (Table 2), while multi-CSF had no mitogenic effect upon peritoneal cells. Such differences in the sensitivities to the action of the CSFs further support the idea that ameboid microglia are a class of mononuclear phagocyte that may be distinguished from tissue macrophage and blood monocytes (Giulian and Baker, 1986).

\section{CSFs as activators of microglia}

As reported for macrophage (North, 1978; Nathan et al., 1980; Dinarello, 1984), ameboid microglia often require activation in order to carry out immunoeffector functions (Giulian and Baker, 


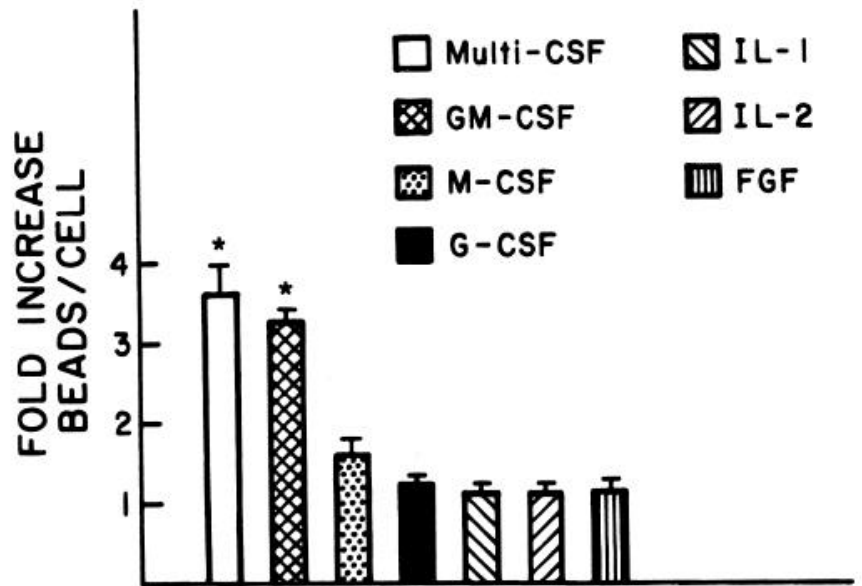

Figure 8. Activation of phagocytosis by colony-stimulating factors. Ameboid microglia in chemically defined medium containing $10 \%$ fetal bovine serum were treated with various immunomodulators or recombinant basic FGF for $6 \mathrm{hr}$ at $37^{\circ} \mathrm{C}$ and then incubated with fluorescently labeled microspheres for $12 \mathrm{hr}$. At the end of the incubation period, cells were washed with chemically defined medium and labeled with DiI-ac-LDL. Data are mean values \pm SEM expressed as the number of microspheres per cell. Concentrations (per ml) of medium included 10 units of m-multi-CSF, 10 units of rm-GM-CSF, 50 units of rh-M-CSF, 50 units of rh-G-CSF, 100 units of rh-IL-1 alpha, 100 units of rh-IL2 , and $100 \mathrm{ng}$ recombinant basic FGF. ${ }^{*} p<0.01$ by Student's $t$ test is statistically significant using the Bonferroni correction (Godfrey, 1985).

1986; Giulian et al., 1986b; Giulian, 1987). We examined the phagocytic activity of ameboid microglia after incubating cells with immunomodulators prior to the presentation of fluorescently labeled polystyrene microspheres. As shown in Figure 7, more microspheres are engulfed by DiI-ac-LDL(+) cells preincubated with GM-CSF than by untreated control cells. The mean number of microspheres engulfed by ameboid cells is significantly increased after exposure to GM-CSF and multiCSF but not to M-CSF, G-CSF, IL-1, IL-2, or FGF (Fig. 8).

\section{CSFs amplify inflammatory responses in the adult CNS}

We considered the possibility that CSFs might promote inflammation within the brain. Activated ameboid microglia or invading macrophage that appear at sites of brain injury can be identified using either the histochemical stain for nonspecific esterase (Ling, 1981) or a fluorescent probe for acetylated LDL receptors (Giulian, 1987). Normal cerebral cortex rarely contained cells that were DiI-ac-LDL(+). However, $48 \mathrm{hr}$ after intracerebral injections of GM-CSF, there was a marked increase in the number of Dil-ac-LDL(+) cells at the site of injection compared with injections of GM-CSF or control injections of PBS (Fig. 9). Similar increases in the number of nonspecific esterase $(+)$ mononuclear phagocytes were also observed at injection sites of multi-CSF (Fig. 10). Quantitation of DiI-ac-LDL $(+)$ cells showed that GM-CSF and multi-CSF were the factors most effective in stimulating the appearance of mononuclear phagocytes within the brain (Fig. 11).

Figure 9. Fluorescence photomicrographs show the increased number of DiI-ac-LDL $(+)$ cells within $48 \mathrm{hr}$ after injection of 10 units of rmGM-CSF $(C)$ into the cerebral cortex of adult rats compared with control
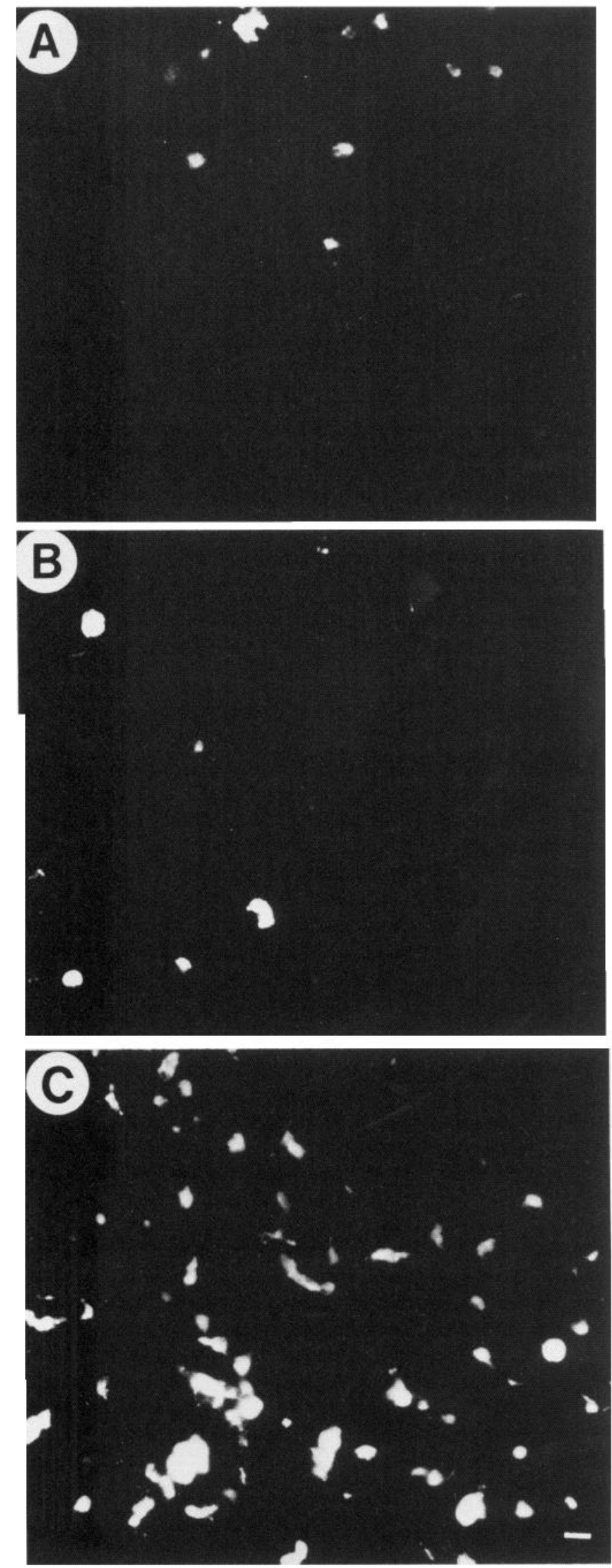

PBS injection sites $(A)$ or to sites with 50 units of rh-M-CSF $(B)$. Scale, $20 \mu \mathrm{m}$. 

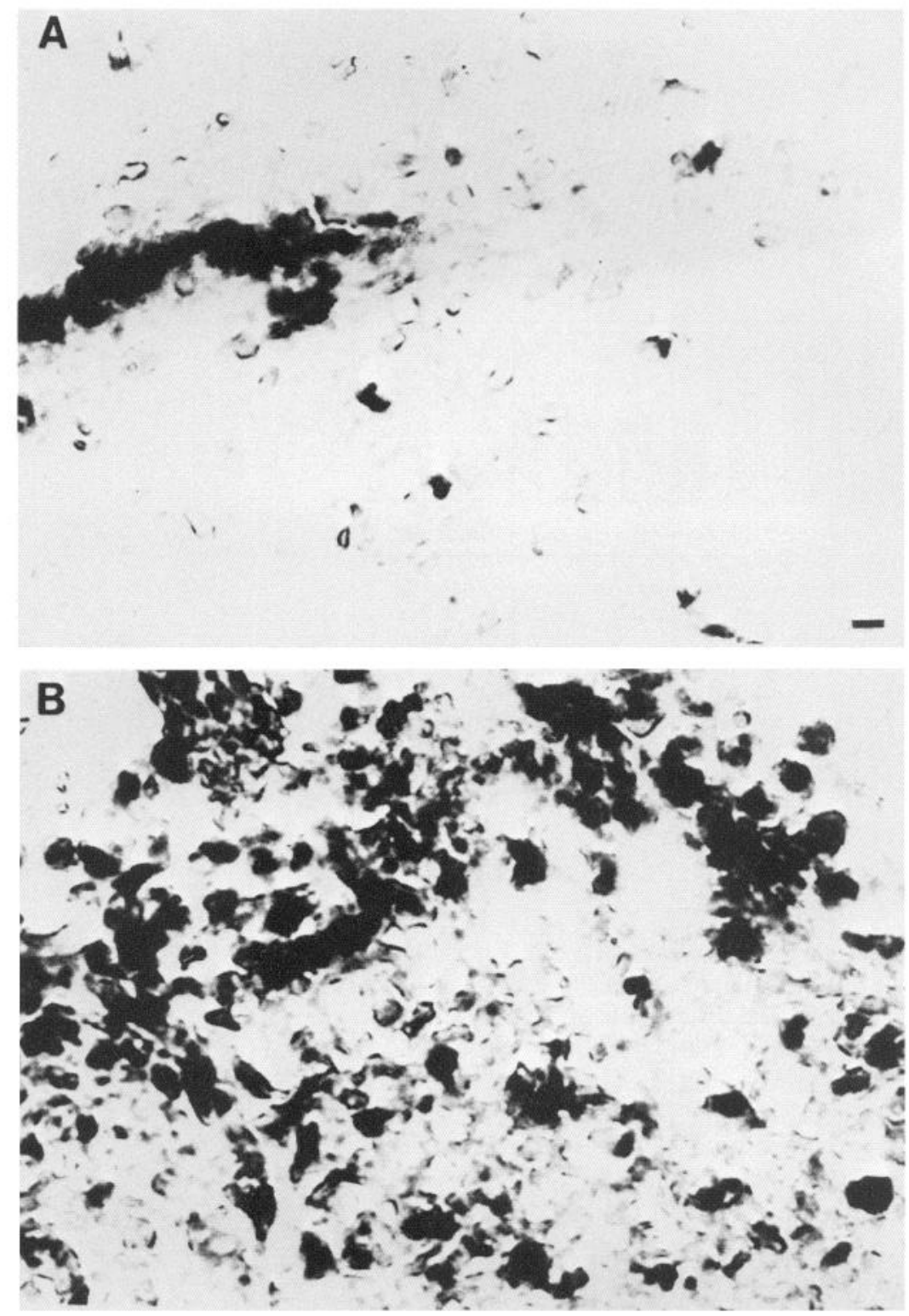

Figure 10. In vivo effects of colonystimulating factors upon adult brain. At $48 \mathrm{hr}$ after injection of 10 units of mmulti-CSF $(B)$, there was a significant increase in the number of nonspecific esterase $(+)$ cells compared with those sites receiving 50 units of rh-G-CSF $(A)$ or PBS alone $(C)$. Scale bar, $20 \mu \mathrm{m}$.

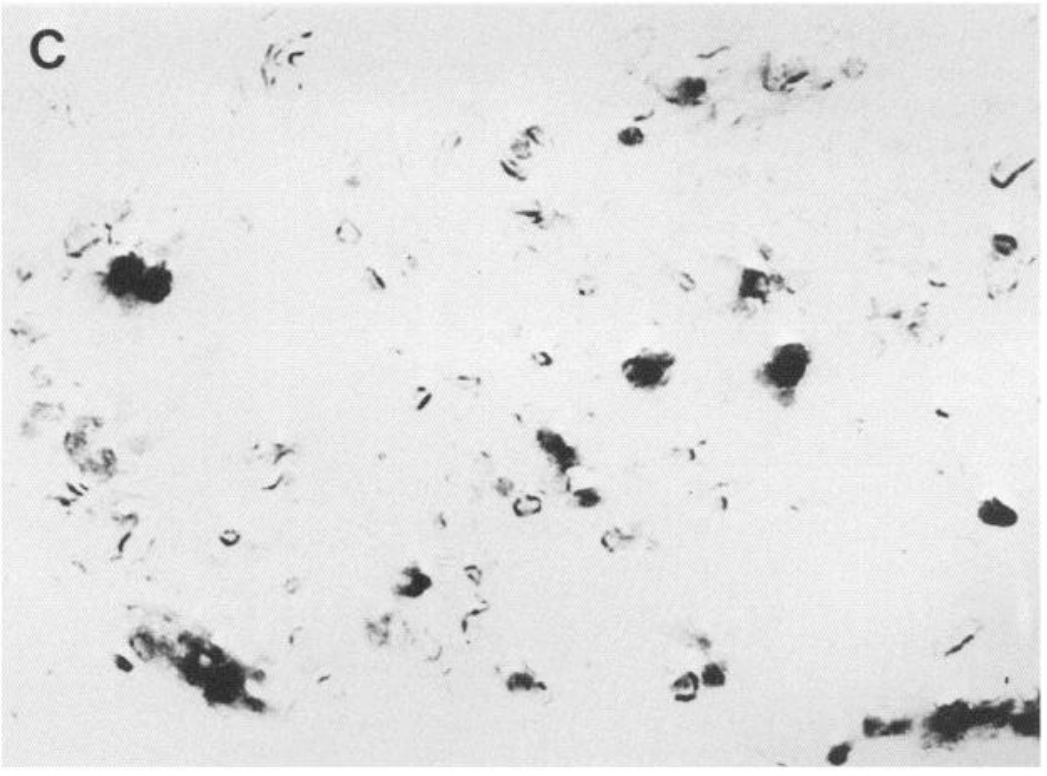




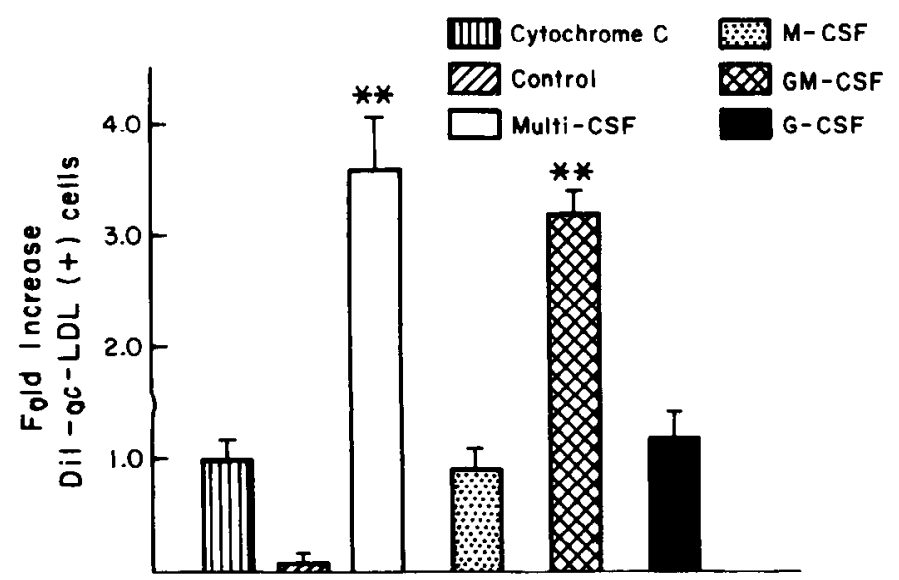

Figure 11. In vivo effects of colony-stimulating factors upon adult brain. At $48 \mathrm{hr}$ after infusion of 10 units of m-multi-CSF or rm-GM$\mathrm{CSF}$, there was a significant increase in the number of Dil-ac-LDL $(+)$ cells found at the site of injection compared with an infusion of $100 \mathrm{ng}$ cytochrome C. Infusions of 50 units of rh-M-CSF or rh-G-CSF did not alter cell number. Data are mean values \pm SEM expressed as the fold increase in total number of DiI-ac-LDL $(+)$ cells seen per injection site compared with PBS vehicle injection. Uninjected sites of cerebral cortex (control) were free of DiI-ac-LDL + ) cells. Each mean value represents at least 5 injections. ${ }^{* *} p<0.005$ by Student's $t$ test using the Bonferroni correction (Godfrey, 1985).

Clearance of debris is an important function of brain mononuclear phagocytes (Rio-Hortega, 1932) and involves a series of cellular behaviors, including chemotaxis to the site of injury, debris recognition, phagocytosis, and movement of debris-laden cells. Fluorescently labeled polystyrene microspheres were coinjected with GM-CSF, M-CSF, G-CSF, or multi-CSF into the cerebral cortex of normal adult rats. We found a more rapid clearance of microspheres at those sites stimulated with GMCSF or multi-CSF (Fig. 12, Table 3). Thus, specific immunomodulators not only stimulated the proliferation and phagocytic activity of ameboid microglia in vitro but also stimulated the appearance and activity of brain mononuclear phagocytes in vivo.

\section{Discussion}

Recent work has shown that ameboid microglia are important effector cells of the CNS that act as phagocytic scavengers, secretors of cytotoxins, and producers of growth factors (Giulian, 1987). In this study we investigated the ability of immunomodulators to influence biologic activity of microglia. We found that only GM-CSF and multi-CSF were potent mitogens for ameboid, as well as activators of phagocytosis. When injected directly into the cerebral cortex of rats, GM-CSF and multi-CSF, but not M-CSF or G-CSF, increased the number of mononuclear phagocytes found at the site of infusion. GM-CSF and multi$\mathrm{CSF}$ also accelerated the clearance of foreign particles from the CNS. We conclude that GM-CSF and multi-CSF are potent activators of brain mononuclear phagocytes and may serve as mediators of inflammatory responses in the brain. Although cell markers to distinguish invading macrophage from ameboid microglia are not yet available, our in in vitro data (Table 1) favor the notion that GM-CSF and multi-CSF directly stimulate microglia in vivo.

Multi-CSF is a mitogen for progenitor hematopoietic cells (Clark and Kamens, 1987). We found multi-CSF to be a mitogen for ameboid microglia but not newborn rat blood monocytes
Table 3. CSFs accelerate clearance of microspheres from the cerebral cortex

\begin{tabular}{lcc} 
Factor & $\begin{array}{l}\text { Microspheres per } \\
\text { section }\end{array}$ & $\begin{array}{l}\text { Clearance } \\
\text { score (\%) }\end{array}$ \\
\hline Control $(n=144)$ & $201 \pm 25$ & 0 \\
M-CSF (168) & $170 \pm 24$ & 15 \\
GM-CSF (144) & $39 \pm 19^{a}$ & 80 \\
G-CSF (48) & $234 \pm 84$ & -15 \\
Multi-CSF (77) & $43 \pm 25^{a}$ & 80
\end{tabular}

Polystyrene microspheres $(0.7 \mu \mathrm{m}$ in diameter) were coinjected with CSFs at a depth of $1.5 \mathrm{~mm}$ into the cerebral cortex of adult rats. The total volume of the injections was $1 \mu \mathrm{l}$ of suspension of microspheres in PBS containing 50 units of rh-M-CSF, 10 units of rm-GM-CSF, 50 units of rh-G-CSF, or 10 units of m-multiCSF. The injection control was $1 \mu$ l of the microsphere-PBS suspension. Animals were sacrificed after $72 \mathrm{hr}$ and the brains cut in the coronal plane with serial sections of $10 \mu \mathrm{m}$ thickness. The total number of microspheres found in section was determined for each animal. Data are mean values \pm SEM expressed as number of microspheres per section of tissue. The clearance score, microspheres removed from brain, was calculated as the percent decrease in number of microspheres when compared to the control injection site. $n=$ number of brain sections scored per group. Statistical analyses compared CSF injected sites with control sites.

${ }^{a} p<0.005$ by Student's $t$ test using the Bonferroni correction.

(Giulian and Baker, 1986) or adult rat resident peritoneal macrophage (Table 1). Such observations support the idea that ameboid microglia are a distinct class of mononuclear phagocyte more similar to bone marrow progenitor cells than to circulating blood monocytes. Although the origin of microglia remains uncertain, our findings are consistent with Rio-Hortega's hypothesis that primitive mesenchymal cells seed the embryonic brain with microglial precursors (Rio-Hortega, 1932).

Further study will be necessary to determine if factors similar to GM-CSF or multi-CSF are produced within the CNS. There are indications that the brain does contain CSF-like biologic activities. Our laboratory (D. Giulian, unpublished observations), for example, has recently found 2 brain proteins that stimulate proliferation of ameboid microglia but not astroglia or oligodendroglia. Morcover, the grcatest concentrations of these mitogens are recovered from brain tissue at periods of microglial proliferation. In vitro studies from Frei and Fontanna (1986) also suggest that a CSF-like biologic activity is produced in cell cultures of brain. The characterization of these factors and the identification of their cellular sources will help to elucidate mechanisms regulating the early phases of brain inflammation. Perhaps the local secretion of brain CSFs helps to control the growth of microglial populations during late embryonic development and at sites of injury.

The brain is often considered to be an immunologically privileged site for it shows a delayed rejection of tissue grafts and normally has a very small population of antigen-presenting mononuclear phagocytes (Medawar, 1947; Head and Griffin, 1985). The in vivo application of CSFs to the brain stimulates a local inflammatory response by increasing both the number and cffector capacities of mononuclear phagocytes. Similar application of immunomodulators may offer new opportunities to treat neurologic disease.

\section{References}

Bottenstein, J. E., and G. H. Sato (1979) Growth of rat neuroblastoma cell line in serum-free supplemental medium. Proc. Natl. Acad. Sci. USA 76: 514-517.

Boya, J., J. Calvo, and A. Prado (1979) The origin of microglial cells. J. Anat. 129: 177-186. 

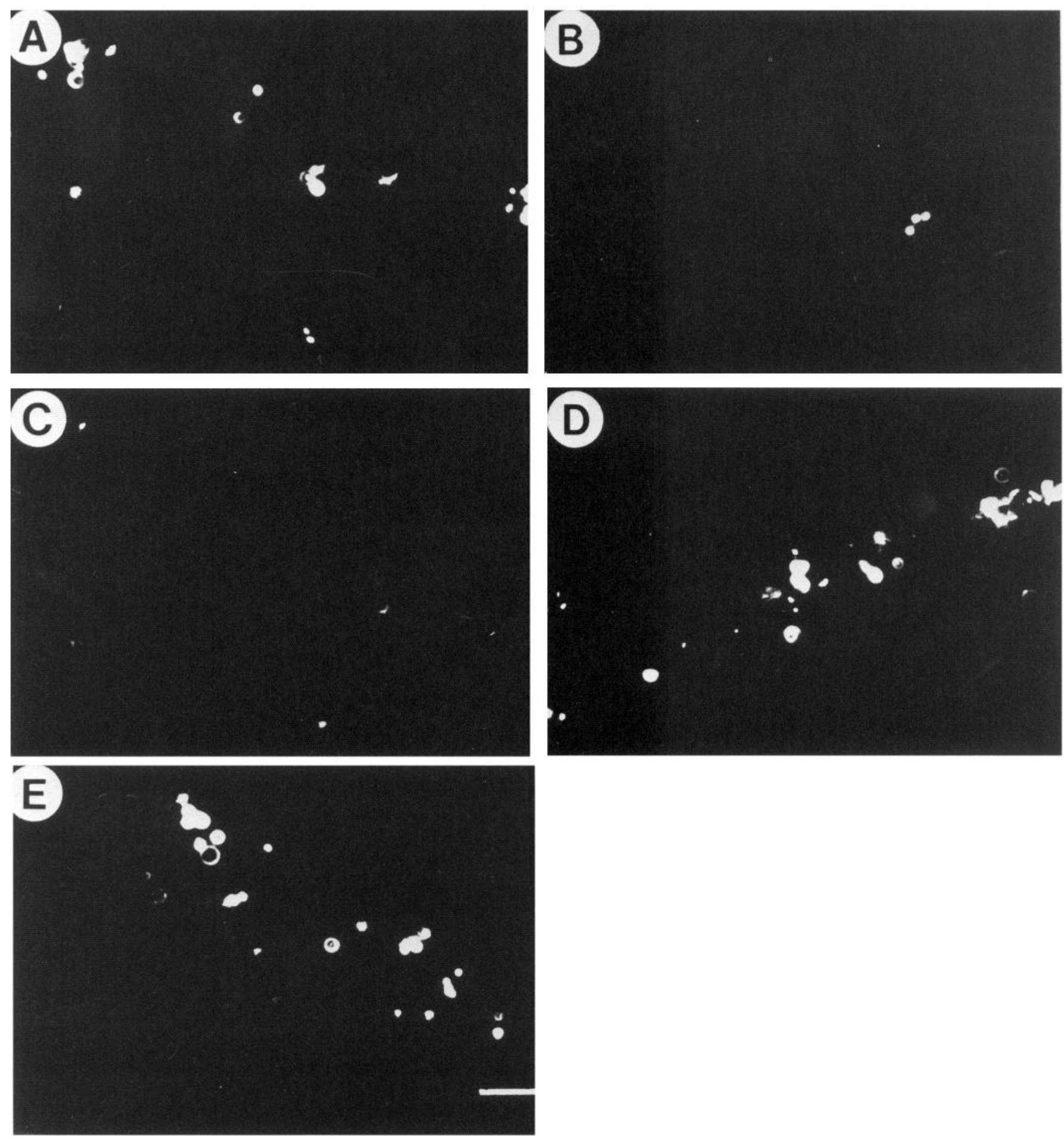

Figure 12. Fluorescence photomicrographs of microsphere clearance from the adult brain. Colony-stimulating factors were co-injected with fluorescently labeled microspheres into the cerebral cortex of adult rats. Clearance of the particles was examined $72 \mathrm{hr}$ later. As shown here, there are fewer microspheres in those sites injected with 10 units of rm-GM-CSF $(B)$ or 10 units of m-multi-CSF $(C)$ compared with PBS controls $(A)$, 50 units of rh-M-CSF $(D)$, or 50 units of rh-G-CSF $(E)$. Scale bar, $20 \mu \mathrm{m}$.

Brierley, J. B., and A. W. Brown (1982) The origin of lipid phagocytes in the central nervous system: I. The intrinsic microglia. J. Comp. Neurol. 211:397-406.

Clark, S. C., and R. Kamens (1987) The human hematopoietic colonystimulating factors. Science 236: 1229-1237.

Daems, W. T. (1980) Peritoneal macrophages. In The Reticuloendothelial System, D. O. Adams, P. J. Edelson, and H. Koren, eds., pp. 549-559, Academic, New York.

Dinarello, C. A. (1984) Interleukin-1. Rev. Infect. Dis. 6: 51-95.
Frei, K., and A. Fontanna (1986) Astrocyte-derived IL-3 as a growth factor for microglia and peritoneal macrophages. J. Immunol. 11: 3521-3527.

Giulian, D. (1987) Ameboid microglia as effectors of inflammation in the central nervous system. J. Neurosci. Res. 18: 155-171.

Giulian, D., and T. J. Baker (1985) Peptides released by ameboid microglia regulate astroglial proliferation. J. Cell Biol. 101: 24112415.

Giulian, D., and T. J. Baker (1986) Characterization of ameboid mi- 
croglia isolated from the developing mammalian brain. J. Neurosci. 6: 2163-2178.

Giulian, D., and L. B. Lachman (1985) Interleukin-1 stimulates astroglial proliferation after brain injury. Science 228: 497-499.

Giulian, D., R. L. Allen, T. J. Baker, and Y. Tomozawa (1986a) Brain peptides and glial growth. 1) Glia-promoting factors as regulators of gliogenesis in the developing and injured central nervous system. J. Cell Biol. 102: 803-811.

Giulian, D., T. J. Baker, L. N. Shih, and L. B. Lachman (1986b) Interleukin-1 of the central nervous system is produced by ameboid microglia. J. Exp. Med. 164: 594-604.

Giulian D., J. Woodward, D. G. Young, J. F. Krebs, and L. B. Lachman (1988a) Interleukin-1 injected into mammalian brain stimulates astrogliosis and neovascularization. J. Neurosci. 8: 2485-2490.

Giulian, D., D. Young, J. Woodward, D. Brown, and L. B. Lachman (1988b) Interleukin-1 is an astroglial growth factor in developing brain. J. Neurosci. 8: 709-714.

Godfrey, K. (1985) Comparing the means of several groups. N. Engl. J. Med. 313: 1450-1456.

Head, J. R., and W. S. T. Griffin (1985) Functional capacity of solid tissue transplants in the brain: Evidence for immunologic privilege. Proc. R. Soc. London [Biol.] 224: 375-387.

Innocenti, G. M., S. Clarke, and H. Koppel (1983) Transitory macrophages in the white matter of the developing visual cortex. II. Development and relations with axonal pathways. Dev. Brain Res. 11. $55-66$.

Konigsmark, B. W., and R. L. Sidman (1963) Origin of brain macrophage in the mouse. J. Neuropathol. 22: 643-676.

Koski, I. R., D. G. Poplack, and R. M. Blaese (1976) A nonspecific esterase stain for the identification of monocytes and macrophages. In In Vitro Methods in Cell Mediated and Tumor Immunity, B. R. Bloom, and I. R. David, eds., pp. 359-362, Academic, New York.

Kreutzberg, G. W., and I. C. D. Barron (1976) $5^{\prime}$ nucleotidase of microglial cells in the facial nucleus during axonal reaction. J. Neurocytol. 7: 601-610.

Kreutzberg, G. W., and M. Graber (1986) Glial reaction in a motor nucleus during regeneration. Tenth International Congress of Neuropathology A415 (abstr.).

Ling, E. A. (1981) The origin and naturc of microglia. In Advances in Cellular Neurobiology, S. Fedoroff and L. Hertz, eds., pp. 33-82, Academic, New York.

Matsumoto, Y., and F. Ikuta (1985) Appearance and distribution of fetal brain macrophages in mice. Cell Tissue Res. 239: 271-278.

Medawar, P. B. (1947) Immunity to homologous grafted skin. III. The fate of skin homografts transplanted to the brain, to subcutaneous tissue, and to the anterior chamber of the eye. Br. J. Exp. Pathol. 29: 58-69.

Metcalf, D. (1985) The granulocyte-macrophage colony-stimulating factors. Science 229: 16-22.

Nathan, C., H. Murray, and Z. Cohn (1980) The macrophage as an effector cell. N. Engl. J. Med. 303: 622-625.

North, R. J. (1978) Concept of activated macrophage. J. Immunol. 121: 806-809.

Oehmichen, M. (1983) Inflammatory cells in the central nervous system. Prog. Neuropathol. 5: 277-335.

Pitas, R. E., T. L. Innerarity, J. N. Weinstein, and R. W. Mahley (1981) Acetoacetylated lipoproteins used to distinguish fibroblasts from macrophages in vitro by fluorescence microscopy. Arterosclerosis $1: 177-$ 185.

Pruss, R. M., P. F. Bartlett, J. Gavrilovic, R. P. Lisak, and S. Rattray (1981) Mitogens for glial cells: Comparison of the response of cultured astrocytes, oligodendrocytes, and Schwann cells. Dev. Brain Res. 2: 19-35.

Rio-Hortega, P. (1932) Microglia. In Cytology and Cellular Pathology of the Nervous System, W. Penfield, ed., pp. 481-584, Hocker, New York. 